\title{
MicroRNA-185 regulates spinal cord injuries induced by thoracolumbar spine compression fractures by targeting transforming growth factor- $\beta 1$
}

\author{
PENGFEI ZHAO, SHAOCHUN WANG, YINGJIE ZHOU, HUAILIANG ZHENG and GANG ZHAO
}

Luoyang Orthopedic-Traumatological Hospital, Luoyang, Henan 471002, P.R. China

Received July 16, 2015; Accepted September 20, 2016

DOI: $10.3892 / \mathrm{etm} .2017 .4052$

\begin{abstract}
The aims of the present study were to examine the expression of transforming growth factor (TGF)- $\beta 1$ and microRNA (miR)-185 in the bone tissue, blood and cerebrospinal fluid of patients with spinal cord injuries and to evaluate the regulation of spinal cord injuries by miR-185. A total of 44 patients with spinal cord injuries induced by thoracolumbar spine compression fractures, who were hospitalized at Luoyang Orthopedic-Traumatological Hospital between June 2012 and February 2015 were enrolled in the present study. Among the patients enrolled, 18 underwent surgery between 1 and 7 days following fracture, and 26 patients underwent surgery between 8 and 14 days following fracture. Bone tissue, peripheral blood and cerebrospinal fluid were subsequently harvested from patients for analysis. Reverse transcription-quantitative polymerase chain reaction was performed to determine the expression of miR-185 and TGF- $\beta 1$ mRNA. Western blotting was performed to evaluate TGF- $\beta 1$ protein expression in bone tissue and ELISA was employed to quantify TGF- $\beta 1$ protein expression in the blood and cerebrospinal fluid. TGF- $\beta 1$ mRNA and protein levels in bone tissue, blood and cerebrospinal fluid from patients who underwent surgery 8-14 days post-fracture were significantly higher than those who underwent surgery $1-7$ days post-fracture $(\mathrm{P}<0.05)$. By contrast, miR-185 levels were significantly lower in bone tissue, blood and cerebrospinal fluid from patients who underwent surgery 8-14 days post-fracture compared with those who underwent surgery 1-7 days post-fracture $(\mathrm{P}<0.05)$. The results of the present study desmonstrate that the upregulation of TGF- $\beta 1$ in the bone tissue, blood and cerebrospinal fluid of patients with spinal cord injuries induced by thoracolumbar spine compression fractures is correlated with the downregulation of miR-185. Furthermore, miR-185 may target TGF- $\beta 1$, affecting
\end{abstract}

Correspondence to: Professor Shaochun Wang, Luoyang Orthopedic-Traumatological Hospital, 82 Qimingnan Road, Luoyang, Henan 471002, P.R. China

E-mail: cxze00@163.com

Key words: microRNA-185, spinal cord injury, thoracolumbar spine compression fracture its transcription and translation, indicating that it serves an important role in spinal cord injuries induced by thoracolumbar spine compression fractures.

\section{Introduction}

The spine is perhaps the most important component of the human skeletal system, as weight, impact or pressure in any area of the body is applied to it (1). Spinal cord injuries most frequently occur in thoracic vertebra 12 to lumbar vertebra 1 of the spine in young adults, accounting for $4.3 \%$ of all body fractures (1). Thoracolumbar spine compression fractures account for $>90 \%$ of all spinal lord fractures and are one of the primary causes of long-term chronic lumbar spinal pain, which severely impacts the quality of life of those suffering from it (2). Furthermore, traumatic spinal cord fracture and dislocation may be fatal (3), with the majority of patients experiencing sensory disturbance of limbs and incontinence (4). Symptoms of paralysis following spinal cord injuries are difficult to recover from and require adequate and appropriate nursing, posing a challenge for clinical treatment (5).

In spinal cord injuries induced by compression fracture, changes in the expression of microRNAs (miR) and mRNAs have been detected; therefore, they may be beneficial in the clinical diagnosis and treatment of spinal cord injuries $(6,7)$. Transforming growth factor (TGF)- $\beta 1$ is a member of the TGF superfamily, which is generated by various types of cells. In the bones, TGF- $\beta 1$ is produced by osteocytes, osteoblasts, osteoclasts and chondrocytes. TGF- $\beta 1$ produced by osteoblasts is immediately bound to the bone matrix (8). It has been demonstrated that TGF- $\beta 1$, which is a potent chemokine, stimulates the synthesis of collagen. TGF- $\beta 1$ increases the growth of extracellular bone matrix and has important regulatory effects on the formation of bones and cartilage (9). During early repair of spinal cord injuries, endogenous TGF- $\beta 1$ expression is rapidly upregulated in the spinal cord, exerting its effect by activating glial cells and phagocytes. As a result, connective tissues are formed, angiogenesis is promoted, extracellular matrix is deposited and collagen is synthesized (10-12). These procedures serve important roles in the repair of nervous tissue lesions. However, the effect of TGF- $\beta 1$ in spinal cord injuries induced by thoracolumbar spine compression fractures remains unclear. In the present study, the expression of TGF- $\beta 1$ and miR-185, and the regulation of TGF- $\beta 1$ by 
miR-185 were evaluated in patients with spinal cord injuries induced by thoracolumbar spine compression fractures.

\section{Materials and methods}

Patients. A total of 44 patients with spinal cord injuries induced by thoracolumbar spine compression fractures, hospitalized at Luoyang Orthopedic-Traumatological Hospital between June 2012 and February 2015, were enrolled in the present study. Among them, 18 patients underwent surgery between 1 and 7 days post-fracture (Group A), and 26 underwent surgery between 8 and 14 days post-fracture (Group B). These patients had no prior history of spinal cord injury and had no history of receiving hormonal treatment, traditional Chinese medicine or radiotherapy. Among the 44 patients, 20 had thoracic spine compression fractures, 18 had lumbar spine compression fractures and 6 had thoracolumbar spine compression fractures. Regarding the reasons for injury, high falling caused eight cases of thoracic spine compression fractures, nine cases of lumbar spine compression fractures and three cases of thoracolumbar spine compression fractures; traffic accidents caused ten cases of thoracic compression fractures, eight cases of lumbar compression fractures and one case of thoracolumbar spine compression fracture; extreme blunt trauma caused two cases of thoracic spine compression fractures, one case of lumbar spine compression fracture and one case of thoracolumbar spine compression fracture. Three types of sample were harvested from patients: i) Bone tissue at the fracture was harvested during surgery and stored in liquid nitrogen at $-80^{\circ} \mathrm{C}$; ii) fasting peripheral blood was harvested on the morning of the day of surgery and subsequently stored in ethylene diamine tetraacetic acid tubes at $-20^{\circ} \mathrm{C}$; iii) a total of $2 \mathrm{ml}$ cerebrospinal fluid was harvested during surgery, followed by centrifugation $(1,500 \times \mathrm{g})$ at $-4^{\circ} \mathrm{C}$ for $10 \mathrm{~min}$, and was stored at $-80^{\circ} \mathrm{C}$. All procedures were approved by the Ethics Committee of Luoyang Orthopedic-Traumatological Hospital. Written informed consent was obtained from all patients or their families.

Reverse transcription-quantitative polymerase chain reaction $(R T-q P C R)$. TRIzol reagent (cat. no. 10606ES60; Yi Sheng Biotechnology Co., Ltd., Shanghai, China) was used to extract total RNA following the manufacturer's protocol. Ultraviolet spectrophotometry (NanoDrop Technologies; Thermo Fisher Scientific, Inc., Wilmington, DE, USA) was used to determine the purity of RNA, by measuring A260/A280. cDNA was subsequently obtained via reverse transcription using the TIANScript II RT kit (cat. no. KR107; Tiangen Biotech Co., Ltd., Beijing, China) according to the manufacturer's protocol. RT-qPCR was performed using iQ5 optical system software (version 2.1; Bio-Rad Laboratories, Inc., Hercules, CA, USA) with SuperReal PreMix (SYBRGreen; cat. no. FP204; Tiangen Biotech, Co., Ltd.) according to the manufacturer's protocol. The primer sequences used were as follows: TGF- $\beta 1$, forward 5'-GGACACCAACTATTGCTTCAG-3' and reverse 5'-TCCAGACTCCAAATGTAG-3'; $\beta$-actin forward 5'-TTC CAGCCTTCCTTCCTGG-3' and reverse 5'-TTGCGCTCA GGAGGAGGAAT-3'. PCR amplification conditions were as follows: Initial denaturation at $95^{\circ} \mathrm{C}$ for $2 \mathrm{~min} ; 30$ cycles of denaturation at $94^{\circ} \mathrm{C}$ for $45 \mathrm{sec}$, annealing at $55^{\circ} \mathrm{C}$ for
$55 \mathrm{sec}$ and elongation at $72^{\circ} \mathrm{C}$ for $1 \mathrm{~min}$; final extension at $72^{\circ} \mathrm{C}$ for $10 \mathrm{~min}$. The $2^{-\Delta \Delta \mathrm{Cq}}$ method (13) was used to calculate TGF- $\beta 1$ levels, and $\beta$-actin was used as a reference gene. Using online prediction websites, including miRanda (http://www.microrna.org/microrna/home.do), TargetScan (http://www.targetscan.org), PicTar (http://pictar.mdc-berlin. de/) and BibiServ (http://bibiserv.techfak.uni-bielefeld.de/), miR-185 was predicted to regulate TGF- $\beta 1$. The forward primers for miR-185 and U6 small nuclear RNA (internal control) were 5'-TGGAGAGAAAGGCAGTTCCTGA-3' and 5'-GCTTCGGCAGCACATATACTAAAAT-3', respectively. The common downstream primer for miR-185 and U6 was 5'-CGCTTCACGAATTTGCGTGTCAT-3'. PCR amplification conditions were as follows: Initial denaturation at $95^{\circ} \mathrm{C}$ for $3 \mathrm{~min} ; 40$ cycles of denaturation at $95^{\circ} \mathrm{C}$ for $12 \mathrm{sec}$, annealing at $62^{\circ} \mathrm{C}$ for $35 \mathrm{sec}$ and elongation at $62-95^{\circ} \mathrm{C}$ for $15 \mathrm{sec}$. The miRcute miRNA qPCR detection kit (SYBR Green) was used to perform qPCR (cat. no. FP401; Tiangen Biotech Co., Ltd.). The $2^{-\Delta \Delta C q}$ method (13) was used to calculate miR-185/U6 levels.

Western blotting. Proteins were extracted and a bicinchoninic acid protein concentration determination kit [cat. no. RTP7102; Real-Times (Beijing) Biotechnology Co., Ltd., Beijing, China] was used to determine protein concentration. Protein samples (20 $\mu \mathrm{g}$ per lane) were separated by $10 \%$ SDS-PAGE and resolved proteins were subsequently transferred to polyvinylidene difluoride membranes on ice (100 V, $2 \mathrm{~h}$ ) and blocked for $1 \mathrm{~h}$ with 5\% skimmed milk at room temperature. Membranes were subsequently incubated at $4^{\circ} \mathrm{C}$ overnight with polyclonal rabbit anti-human TGF- $\beta 1$ primary antibody (1:500; cat. no. ab92486; Abcam, Cambridge, MA, USA) and rabbit anti-human $\beta$-actin primary antibody (1:5,000; cat. no. ab129348; Abcam). Following extensive washing, the membranes were incubated with polyclonal goat anti-rabbit secondary antibody conjugated with horseradish peroxidase (1:3,000; cat. no. ab6721; Abcam) for $1 \mathrm{~h}$ at room temperature. Membranes were developed using an enhanced chemiluminescence detection kit (cat. no. FDO0142; Oddfoni Biological Technology Co., Ltd., Nanjing, China) for imaging. To acquire and analyze imaging signals, Image lab software (version 3.0; Bio-Rad) was used. The content of target protein was expressed as a relative value against $\beta$-actin.

ELISA. Blood and cerebrospinal fluid underwent determination of TGF- $\beta 1$ concentration by ELISA according to the manufacturer's protocol (TGF- $\beta 1$ ELISA kit; cat. no. ab100674; Abcam). Briefly, $50 \mu 1$ control and $10 \mu 1$ tissue samples were seeded onto wells in an assay plate, followed by $40 \mu \mathrm{l}$ sample dilution reagent. Horseradish peroxidase-labeled antibody $(100 \mu \mathrm{l})$ was subsequently added to all wells except for the blank, followed by incubation at $37^{\circ} \mathrm{C}$ for $1 \mathrm{~h}$ prior to five plate washes. Substrates $(50 \mu \mathrm{l})$ were added prior to incubation at $37^{\circ} \mathrm{C}$ for $15 \mathrm{~min}$. Finally, stop solution $(50 \mu \mathrm{l})$ was added to each well and the determination of optical density at $450 \mathrm{~nm}$ was performed within $15 \mathrm{~min}$ using a Multiskan FC Microplate Photometer (Thermo Fisher Scientific, Inc., Waltham, MA, USA).

Statistical analyses. Results were analyzed using SPSS version 18.0 (SPSS, Inc., Chicago, IL, USA). The data were presented as mean \pm standard deviation. Multi-group measurements 
were subjected to one-way analysis of variance. In cases of homogeneity of variance, least significant difference and Student-Newman-Keuls methods were used; in cases of heterogeneity of variance, Dunnett's T3 or Tamhane's T2 method was used. $\mathrm{P}<0.05$ was considered to indicate a statistically significant difference.

\section{Results}

Expression of TGF- $\beta 1 \mathrm{mRNA}$ in patients with spinal cord injuries induced by thoracolumbar spine compression fractures increases with time following injury. RT-qPCR was performed in order to determine levels of TGF- $\beta 1 \mathrm{mRNA}$. The data indicated that TGF- $\beta 1$ mRNA levels in the bone tissues, blood and cerebrospinal fluid of Group B were significantly higher than those in Group A ( $\mathrm{P}<0.05$; Fig. 1). This suggests that the expression of TGF- $\beta 1 \mathrm{mRNA}$ in patients with spinal cord injuries induced by thoracolumbar spine compression fractures increases with time following injury.

Expression of TGF- $\beta 1$ protein in patients with spinal cord injuries induced by thoracolumbar spine compression fractures is increased with time following injury. To measure TGF- $\beta 1$ protein expression, western blotting and ELISA were used. Results from western blotting indicated that TGF- $\beta 1$ protein expression was significantly higher in the bone tissue of Group B than those in Group A $(\mathrm{P}<0.05$; Fig. 2A), which is consistent with the trend of TGF- $\beta 1$ mRNA expression in bone tissues. ELISA indicated that TGF- $\beta 1$ protein expression levels were significantly higher in the blood and cerebrospinal fluid of Group B than those in Group A ( $\mathrm{P}<0.05$; Fig. $2 \mathrm{~B}$ and $\mathrm{C})$, which is consistent with the trends of TGF- $\beta 1$ mRNA expression in blood and cerebrospinal fluid. These results indicate that the expression of TGF- $\beta 1$ protein in patients with spinal cord injuries induced by thoracolumbar spine compression fractures is increased with time following injury.

Expression of miR-185 in patients with spinal cord injuries induced by thoracolumbar spine compression fractures is reduced with time following injury. To measure miR-185 expression, RT-qPCR was performed. The data indicated that the miR-185 levels in bone tissues, blood and cerebrospinal fluid of Group B were significantly lower than those in Group A $(\mathrm{P}<0.01$; Fig. 3). These results suggest that the expression of miR-185 in patients with spinal cord injuries induced by thoracolumbar spine compression fractures decreases with time following injury.

\section{Discussion}

Thoracic spine compression fractures typically induce spinal cord injuries (14). Deformation of the spinal canal, which is where the spinal cord is located, induced by thoracolumbar spine compression fractures may directly or indirectly damage spinal nerves. At present, there is no effective method to directly repair damaged spinal nerves (15). Notably, intervening in cellular and molecular mechanisms following spinal cord injury may inhibit secondary injuries to the spinal cord and serve a role in its repair.
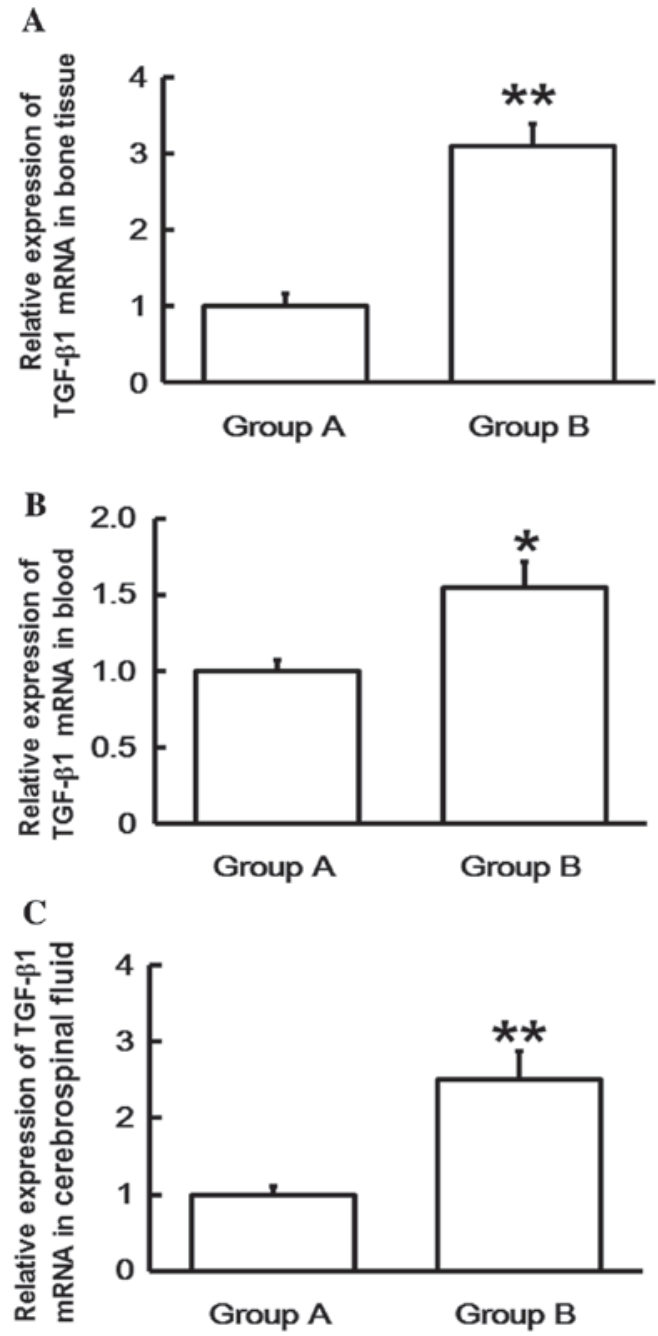

Figure 1. Expression of TGF- $\beta 1 \mathrm{mRNA}$ in (A) bone tissue (B) blood and (C) cerebrospinal fluid. Reverse transcription-quantitative polymerase chain reaction was performed to measure the levels of mRNA. Group A underwent surgery 1-7 days following fracture and group B underwent surgery 8-14 days following fracture. ${ }^{*} \mathrm{P}<0.05$ compared with group $\mathrm{A} ;{ }^{* *} \mathrm{P}<0.01$ compared with group A. TGF, transforming growth factor.

TGF- $\beta 1$, an important coupling agent in the process of bone reconstruction, has an important regulatory effect on bone reconstruction (16). In the present study, TGF- $\beta 1$ mRNA and protein levels were significantly higher in the bone tissues of patients who underwent surgery 8-14 days following fracture compared with those that underwent surgery 1-7 days following fracture. In the bone tissue, osteoblasts are one of the most sensitive cell lines to the mitogenetic effect of TGF- $\beta 1$ (17). Pfeilschifter et al (18) showed that TGF- $\beta$ is positively correlated with human bone remodeling and formation. Additionally, Joyce et al (19) demonstrated that subperiosteal injection of various concentrations of TGF- $\beta 1$ induces osteogenesis and cartilage formation. Furthermore, Centrella and McCarthy (20) suggested that osteogenic or platelet-derived TGF- $\beta 1$ is able to bidirectionally stimulate DNA synthesis in the osteoblasts of fetal mouse skulls and fetal bovine bones, and the synthetic rate of DNA increases, reaches its peak and then decreases as TGF- $\beta 1$ levels steadily increase. The results of the present study are similar to the aforementioned observations (18-20), therefore, it has been demonstrated that 
A
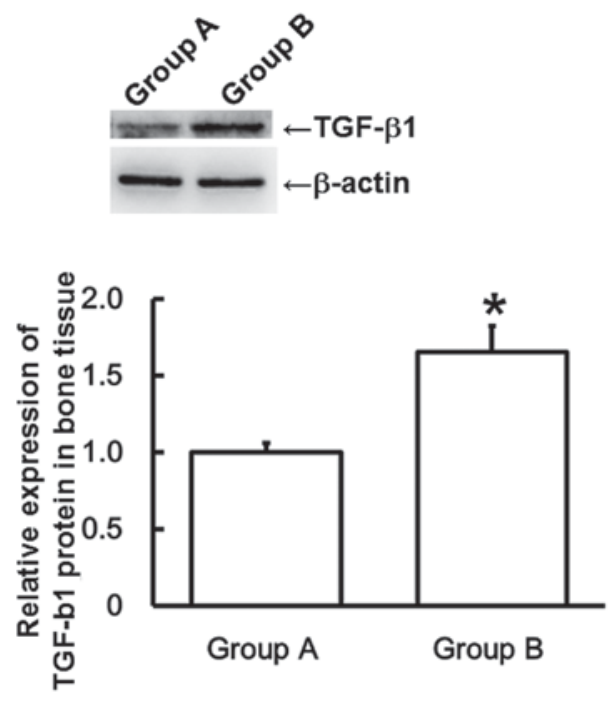

B

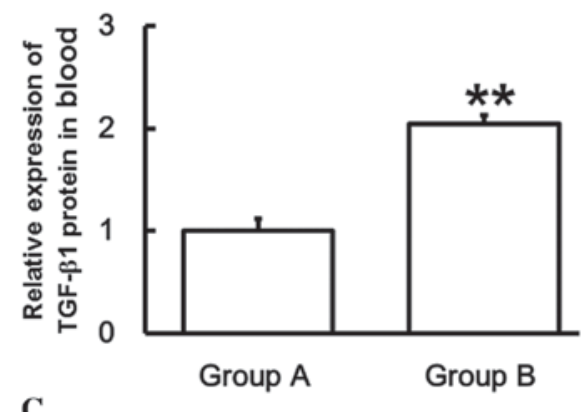

C

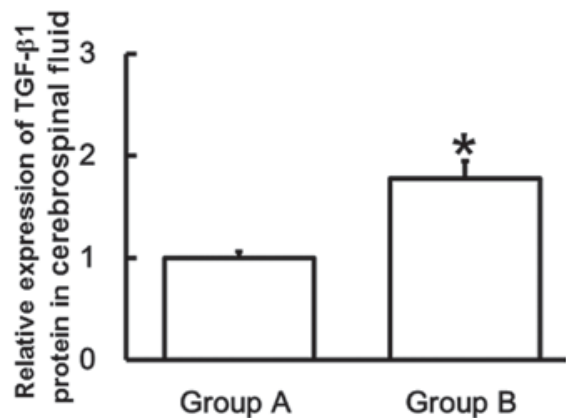

Figure 2. Expression of TGF- $\beta 1$ protein in (A) bone tissue, (B) blood and (C) cerebrospinal fluid. Western blotting was performed to determine TGF- $\beta 1$ protein expression in bone tissue and ELISA was used to measure TGF- $\beta 1$ protein expression in blood and cerebrospinal fluid. Group A underwent surgery 1-7 days following fracture and group B underwent surgery 8-14 days following fracture. " $\mathrm{P}<0.05$ compared with group A; ${ }^{* *} \mathrm{P}<0.01$ compared with group A. TGF, transforming growth factor.

upregulation of TGF- $\beta 1$ serves important roles in skeletal repair and regeneration.

Similar to the results from bone tissues, TGF- $\beta 1$ mRNA and protein levels in the blood or cerebrospinal fluid of patients who underwent surgery 8-14 days following fracture were significantly higher than those who underwent surgery 1-7 days following fracture. A previous study has reported that TGF- $\beta 1$ expression in motor neurons of the spinal cord is associated with the regulation of secondary injuries in the spinal cord (21). Tyor et al (22) identified that inhibition of TGF- $\beta 1$ following spinal cord injury may reduce the number of secondary injuries and the accumulation of monocyte-macrophages in injury regions. Intravenous injection of TGF- $\beta 1$ in rats following spinal cord injury reduces the injury area by $50 \% 48 \mathrm{~h}$ post-injection, compared with a control group (23). Romão et al (24) also observed that TGF- $\beta 1$ mRNA expression increases with time following spinal cord injury, reaching its peak on day 7. Additionally, Gudi et al (25) determined that TGF- $\beta 1$ is important in the regulation of neuronal survival and that TGF- $\beta 1$ selectively upregulates the expression of endogenous neurotrophic factors with synergistic effects. Furthermore, an association between TGF- $\beta 1$ and various central nervous system diseases has been identified. In ischemic brain damage, TGF- $\beta 1$ exerts its neuroprotective effects by reducing the concentration of calcium ions, activating the endothelial cells in ischemic areas and promoting the proliferation of blood capillaries (26). These results suggest that injuries in the spinal cord may stimulate the upregulation of TGF- $\beta 1$ in the body to try to activate the repair and regeneration of the spinal cord, and to reduce inflammation.
miRNAs may interfere with mRNAs and affect their translation (27). Regulation by miRNA increases or decreases mRNA expression to mediate the activities of coding genes of proteins and serves an important role in the occurrence and development of tumors $(28,29)$. In the present study, bioinformatics was used to predict the upstream genes that regulate TGF- $\beta 1$ and it was determined that miR-185 may be closely associated with TGF- $\beta 1$. A recent study has demonstrated that miR-185 upregulates the TGF- $\beta 1$ signaling pathway in chronic benzene poisoning (30). In addition, Kim et al (31) reported that miR-185 inhibits cardiac hypertrophy via multiple signaling pathways. Ma et al (32) demonstrated that miR-185 inhibits proliferation and induces the apoptosis of clear cell renal cell carcinoma cells. Furthermore, Bao et al (33) reported that miR-185 is able to target suppressors of cytokine signaling 3 and thus inhibit the functional disorder of $\beta$ cells induced by diabetes. Fu et al (34) have recently indicated that miR-185 targets c-met and inhibits human breast cancer cell proliferation and metastasis, whereas Wang et al (35) have reported that miR-185 has similar effects in breast cancer cells and targets the vascular endothelial growth factor A gene.

In conclusion, the present study demonstrated that miR-185 may target TGF- $\beta 1$ to affect its transcription and translation and thus serve an important role in spinal cord injury induced by thoracolumbar spine compression fracture. Bone tissues, blood and cerebrospinal fluid were harvested as research samples. The fact that miR-185 and TGF- $\beta 1$ expression was detected in the blood circulation demonstrates that miR-185 may be useful as a diagnostics tool, while the expression of miR-185 and TGF- $\beta 1$ in bone tissues and cerebrospinal fluid represents the physiological status of the respective tissues (36). However, further studies are 
A

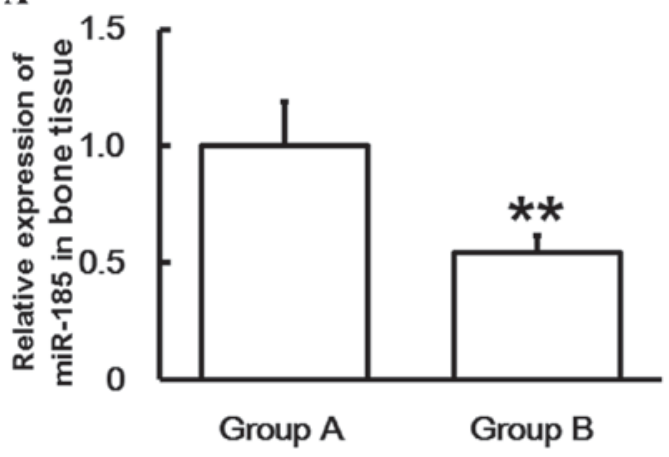

B

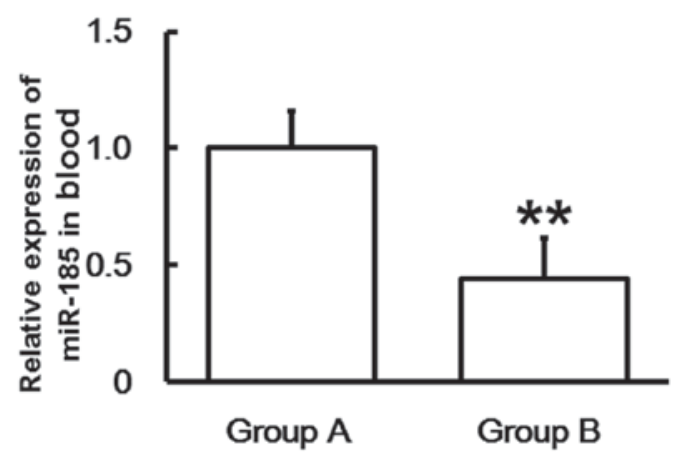

C

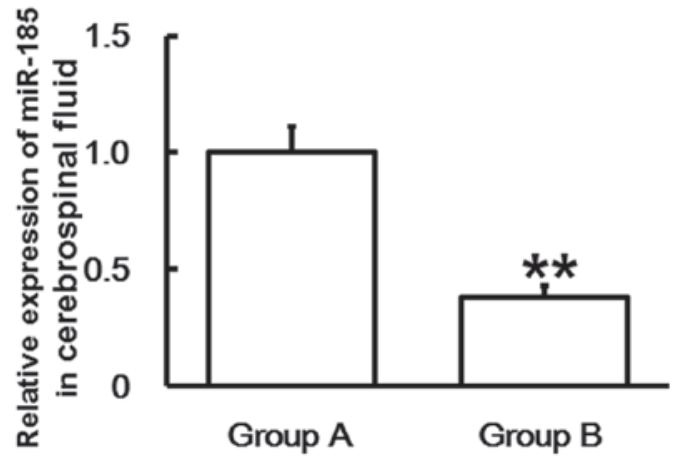

Figure 3. Expression of miR-185 in (A) bone tissue, (B) blood and (C) cerebrospinal fluid. Reverse transcription-quantitative polymerase chain reaction was performed to measure mRNA levels. Group A underwent surgery 1-7 days following fracture and group B underwent surgery 8-14 days following fracture. ${ }^{* * *} \mathrm{P}<0.01$ compared with group A. miR, microRNA.

required to elucidate direct evidence regarding the association between TGF- $\beta 1$ regulation by miR-185 and spinal cord injuries induced by thoracolumbar spine compression fractures.

\section{Acknowledgements}

The present study was supported by Luoyang Orthopedic-Traumatological Hospital. The authors would also like to thank Professor Xinmin Pan from the Department of Forensic Pathology, Henan University of Science and Technology.

\section{References}

1. Silverman SL: The clinical consequences of vertebral compression fracture. Bone 13: (Suppl 2) S27-S31, 1992.

2. Brown DB, Gilula LA, Sehgal M and Shimony JS: Treatment of chronic symptomatic vertebral compression fractures with percutaneous vertebroplasty. AJR Am J Roentgenol 182: 319-322, 2004
3. Kwon BK, Tetzlaff W, Grauer JN, Beiner J and Vaccaro AR: Pathophysiology and pharmacologic treatment of acute spinal cord injury. Spine 4: 451-464, 2004.

4. Hao D, He L and Yuan F: Late complications in patients with spinal cord injuries and related factors. Zhongguo Jizhu Jisui Zazhi 15: 267-270, 2005.

5. Lee KZ and Chang YS: Recovery of the pulmonary chemoreflex and functional role of bronchopulmonary C-fibers following chronic cervical spinal cord injury. J Appl Physiol (1985) 117: 1188-1198, 2014.

6. Murata K, Ito H, Yoshitomi H, Yamamoto K, Fukuda A, Yoshikawa J, Furu M, Ishikawa M, Shibuya H and Matsuda S: Inhibition of miR-92a enhances fracture healing via promoting angiogenesis in a model of stabilized fracture in young mice. J Bone Miner Res 29: 316-326, 2014.

7. Sheyn D, Kallai I, Tawackoli W, Cohn Yakubovich D, Oh A, Su S, Da X, Lavi A, Kimelman-Bleich N, Zilberman Y, et al: Gene-modified adult stem cells regenerate vertebral bone defect in a rat model. Mol Pharm 8: 1592-1601, 2011.

8. Hulth A: Current concepts of fracture healing. Clin Orthop Relat Res 249: 265-284, 1989.

9. Tatsuyama K, Maezawa Y, Baba H, Imamura Y and Fukuda M: Expression of various growth factors for cell proliferation and cytodifferentiation during fracture repair of bone. Eur J Histochem 44: 269-278, 2000.

10. Kiefer R, Streit WJ, Toyka KV, Kreutzberg GW and Hartung HP: Transforming growth factor-beta 1: A lesion-associated cytokine of the nervous system. Int J Dev Neurosci 13: 331-339, 1995.

11. Flanders KC, Ren RF and Lippa CF: Transforming growth factor-betas in neurodegenerative disease. Prog Neurobiol 54 $71-85,1998$

12. Hiraizumi Y, Fujimaki E, Transfeldt EE, Kawahara N, Fiegel VD, Knighton D and Sung JH: The effect of the platelet derived wound healing formula and the nerve growth factor on the experimentally injured spinal cord. Spinal Cord 34: 394-402, 1996.

13. Livak KJ and Schmittgen TD: Analysis of relative gene expression data using real-time quantitative PCR and the 2(-Delta Delta C(T)) Method. Methods 25: 402-408, 2001.

14. Jia L: Modern spinal surgery. 1st edition. People's Military Medical Press, Beijing, pp848-859, 2007.

15. Tian W: Practical Orthopedics. 1st edition. People's Medical Publishing House, Beijing, pp562-563, 2008.

16. Wu T, Liu Y, Fan Z, Xu J, Jin L, Gao Z, Wu Z, Hu L, Wang J, Zhang C, et al: miR-21 Modulates the Immunoregulatory Function of Bone Marrow Mesenchymal Stem Cells Through the PTEN/Akt/TGF- $\beta 1$ Pathway. Stem Cells 33: 3281-3290, 2015.

17. Canalis E, McCarthy T and Centrella M: Growth factors and the regulation of bone remodeling. J Clin Invest 81: 277-281, 1988.

18. Pfeilschifter J, Diel I, Scheppach B, Bretz A, Krempien R, Erdmann J, Schmid G, Reske N, Bismar H, Seck T, et al: Concentration of transforming growth factor beta in human bone tissue: Relationship to age, menopause, bone turnover and bone volume. J Bone Miner Res 13: 716-730, 1998

19. Joyce ME, Roberts AB, Sporn MB and Bolander ME: Transforming growth factor-beta and the initiation of chondrogenesis and osteogenesis in the rat femur. J Cell Biol 110: 2195-2207, 1990

20. Centrella M, McCarthy TL and Canalis E: Transforming growth factor beta is a bifunctional regulator of replication and collagen synthesis in osteoblast-enriched cell cultures from fetal rat bone. J Biol Chem 262: 2869-2874, 1987.

21. Unsicker K and Krieglstein K: TGF-betas and their roles in the regulation of neuron survival. Adv Exp Med Biol 513: 353-374, 2002.

22. Tyor WR, Avgeropoulos N, Ohlandt G and Hogan EL: Treatment of spinal cord impact injury in the rat with transforming growth factor-beta. J Neurol Sci 200: 33-41, 2002.

23. Want $\mathrm{T}$ and Feng $\mathrm{Z}$ : Polypeptide growth factors and spinal cord injury. Health Science and Technology Publishing House in Xinjiang. Fitst Edition, Urumqi, pp104-105, 2003.

24. Romão Junior JE, Haiashi AR, Vidonho Junior AF, Abensur H, Quintaes PS, Araújo MR, Noronha IL, Santos FR and Machado MM: Causes and prognosis of acute renal failure in elderly patients. Rev Assoc Med Bras (1992) 46: 212-217, 2000 (In Portuguese).

25. Gudi V, Škuljec J, Yildiz Ö, Frichert K, Skripuletz T, Moharregh-Khiabani D, Voss E, Wissel K, Wolter S and Stangel M: Spatial and temporal profiles of growth factor expression during CNS demyelination reveal the dynamics of repair priming. PLoS One 6: e22623, 2011. 
26. Kim D, Schallert T, Liu Y, Browarak T, Nayeri N, Tessler A Fischer and Murray M: Transplantation of genetically modified fibroblasts expressing BDNF in adult rats with a subtotal hemisection improves specific motor and sensory functions. Neurorehabil Neural Repair 15: 141-150, 2001.

27. Zhao X, Mohan R, Özcan S and Tang X: MicroRNA-30d induces insulin transcription factor MafA and insulin production by targeting mitogen-activated protein 4 kinase 4 (MAP4K4) in pancreatic $\beta$-cells. J Biol Chem 287: 31155-31164, 2012.

28. Chen K and Rajewsky N: The evolution of gene regulation by transcription factors and microRNAs. Nat Rev Genet 8: 93-1037, 2007.

29. Lewis BP, Burge CB and Bartel DP: Conserved seed pairing, often flanked by adenosines, indicates that thousands of human genes are microRNA targets. Cell 120: 15-20, 2005.

30. Bai W, Chen Y, Yang J, Niu P, Tian L and Gao A: Aberrant miRNA profiles associated with chronic benzene poisoning. Exp Mol Pathol 96:426-430, 2014.

31. Kim JO, Song DW, Kwon EJ, Hong SE, Song HK, Min CK and Kim DH: miR-185 Plays an Anti-Hypertrophic Role in the Heart via Multiple Targets in the Calcium-Signaling pathways. PLoS One 10: e0122509, 2015.
32. Ma X, Shen D, Li H, Zhang Y, Lv X, Huang Q, Gao Y, Li X, Gu L, Xiu S, et al: MicroRNA-185 inhibits cell proliferation and induces cell apoptosis by targeting VEGFA directly in von Hippel-Lindau-inactivated clear cell renal cell carcinoma. Urol Oncol 33: 169.e1-11, 2015.

33. Bao L,FuX, Si M, Wang Y,Ma R, Ren X and Lv H: MicroRNA-185 targets SOCS3 to inhibit beta-cell dysfunction in diabetes. PLoS One 10: e0116067, 2015

34. Fu P, DU F, Yao M, Lv K and Liu Y: MicroRNA-185 inhibits proliferation by targeting c-Met in human breast cancer cells. Exp Ther Med 8: 1879-1883, 2014.

35. Wang R, Tian S, Wang HB, Chu DP, Cao JL, Xia HF and Ma X: MiR-185 is involved in human breast carcinogenesis by targeting Vegfa. FEBS Lett 588: 4438-4447, 2014.

36. Chang CZ, Wu SC, Lin CL and Kwan AL: Curcumin, encapsulated in nano-sized PLGA, down-regulates nuclear factor $\kappa \mathrm{B}$ (p65) and subarachnoid hemorrhage induced early brain injury in a rat model. Brain Res 1608: 215-224, 2015. 